\title{
«И откуда Ваши сваты?» \\ (реалии и ментальные образы пространства в свадебном обряде калмыков)*
}

Татьяна И. Шараева

Калмыцикий научный центр Российской академии наук, Российская Федерация

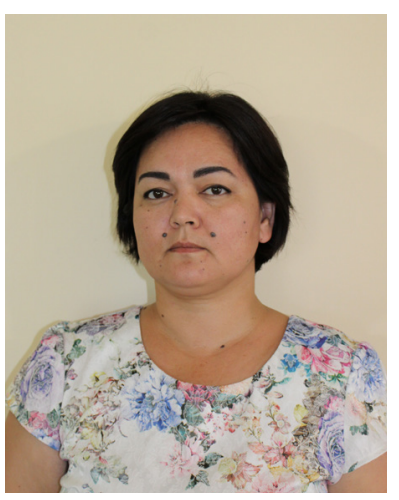

В статье рассматриваются представления об освоенном пространстве во взаимосвязи с различиями в свадебных обрядовых комплексах у представителей различных субэтнических групп калмыков современности. Этническое и административное деление у калмыков всегда были тесно переплетены между собой. Термин «улус» маркировал и территориальную единицу, и людей его населяющих, связанных между собой по этническому признаку. Пространство, принадлежащее определенному улусу, состояло из концентрических кругов, внутри каждого из которых был другой круг, а центром освоенного локуса в них - место конкретного проживания человека, его родственного социума. Это освоенное пространство воспринималось «своей землей», землей предков. К началу ХХІ в. у калмыков сложилась форма восприятия «своего» пространства через сохранившуюся практику улусного деления, накладываемую на территорию современной республики, что продолжает быть основой принадлежности ее определенной субэтнической группе, представители которой определяются по географическому признаку.

Такое восприятие пространства у современных калмыков - сельских и городских - учитывается при проведении свадьбы, связано с четырехчастным делением пространства по горизонтали, где название стороны света привязывается к месту проживания определенной субэтнической группы. Будущая свадьба и поездка к сватам, различия в проведении свадебных ритуалов и обрядов, а также в доставляемых пищевых наборах и различных предметах, связаны с понятием «инаковости», «чужом», временном перемещении в сходном, но «ином/чужом» пространстве, маркируемое в калмыцком языке термином хәр һазр. Движение и нахождение в «чужой земле» определило проведение обязательных обрядов подношения духам-хозяевам местности и предкам на значимых границах кругов освоенных территорий, связанных с вертикальным трехчастным делением пространства. Достижение центра «чужой земли» и нахождение в жилом пространстве жилища сохраняет в современных реалиях пространственно-семантический код традиционной культуры у калмыков. В обрядовом пространстве достигается компромисс сторон, чтобы соблюсти «свои законы».

Источниковой базой исследования выступили полевые материалы автора по свадебной обрядности, собранные в Калмыкии в 2008-2010 г2., в 2018-2019 г2.

Ключевые слова: калмыки; Калмыкия; свадьба; свадебная обрядность; сваты; пространство; этнические группы

" Исследование проведено в рамках государственной субсидии - проект «Комплексное исследование процессов общественнополитического и культурного развития народов Юга России» (регистрационный номер АААА-А19-119011490038-5).

\section{Для циитирования:}

Шараева Т. И. «И откуда Ваши сваты?» (реалии и ментальные образы пространства в свадебном обряде калмыков) [Электронный ресурс] // Новые исследования Тувы. 2019, № 3. URL: https://nit.tuva.asia/nit/article/view/870 (дата обращения: дд.мм.гг.). DOI: 10.25178/nit.2019.3.11

Шараева Татьяна Исаевна - старший научный сотрудник отдела истории, археологии и этнологии Калмыцкого научного центра Российской академии наук. Адрес: 358000, Россия, г. Элиста, ул. им. И. К. Илишкина, д. 8. Тел.: +7 (84722) 3-55-06. Эл. адрес: sharaevati@yandex.ru ORCID ID: 0000-0002-2242-5136

Sharaeva Tatyana Isayevna, Candidate of History, Senior Research Associate, Department of History, Archaeology and Ethnology, Kalmyk Scientific Center, Russian Academy of Sciences. Postal address: 8 Ilishkin St., 358000 Elista, Russian Federation. Tel.: +7 (84722) 3-55-06. E-mail: sharaevati@yandex.ru 


\title{
'So where are your in-laws from?': Realities and mental images within the space of Kalmyk wedding rites)"
}

\author{
Tatyana I. Sharaeva \\ Kalmyk Scientific Center of the Russian Academy of Sciences, Russian Federation
}

\begin{abstract}
The article examines the ideas of explored space in its relation to differences between wedding rites inherent to diverse subethnic groups of the today Kalmyks. Ethnic and administrative divisions of the Kalmyks have always been closely linked. The term 'ulus' denoted both a territorial unit and its ethnically bound population. The space assigned to a certain ulus was constituted by a number of consecutive circles, with the focus in the place of residence of an individual and the community of their kinsfolk. This cultivated area was perceived as one's 'own land', their 'ancestral territory'. By the early 21st century, Kalmyks have developed a form of perceiving one's 'own' space through the prism of ulus division as imposed on present-day boundaries within the republic. This still serves as a foundation stone of 'belonging' to a certain sub-ethnic group 'determined' geographically.

Such a perception of space among modern Kalmyks - both rural and urban dwellers - is taken into consideration during wedding rites. It stems from the four-part horizontal division of space whereby cardinal points are tied to residential areas of certain sub-ethnic groups. The future wedding and a journey to the potential in-laws, differences in wedding rites, as well as the to-be-delivered food sets and utensils are tied to the concept of 'otherness', 'alienness', to a temporal shift into a similar but 'alien' space marked by the Kalmyk term 'khär yazr' (Kalm. xәp hasp). The idea of crossing into and staying in an 'alien land' gave rise to compulsory ceremonial offerings to master spirits of the land and ancestors at borders of essential circles connected to the vertical three-part division of space. Reaching the center of an 'alien land' and stay in a dwelling has preserved the spatial semantic code of traditional culture. In the ritual landscape the parties must reach a compromise to comply with one's 'own laws'.

For its sources, the article relies on the materials on wedding rites collected by the author during fieldwork in Kalmykia in 2008-2010 and 2018-2019.
\end{abstract}

Keywords: Kalmyks; Kalmykia; wedding; wedding rites; in-laws; space; ethnic groups.

"The research was performed with a government subsidy - project 'Socio-Political and Cultural Development of South Russia's Peoples: a Comprehensive Research of Respective Processes' (State Reg. No. AAAA-A19-119011490038-5).

\section{For citation:}

Sharaeva T. I. 'So where are your in-laws from?': Realities and mental images within the space of Kalmyk wedding rites). The New Research of Tuva. 2019, № 3. URL: https://nit.tuva.asia/nit/article/view/870 (access date ...). DOI: 10.25178/ nit.2019.3.11

\section{Введение}

Современная свадебная обрядность калмыков - это соединение традиционных представлений и мировоззренческих основ, обычаев и обрядов, а также различных трансформаций, начавшихся с середины XX века, и включения инноваций. Исследователи неоднократно отмечали, что, несмотря на наличие общеэтнической модели свадьбы у калмыков, в ней имелись локальные особенности, характерные для представителей различных этнических групп (шире - субэтнических групп) и собственная свадебная символика.

В изучении калмыцкой свадебной обрядности много лакун, одна из них - взаимосвязь субэтнических особенностей в обрядовой сфере с освоенным пространством и хозяйственным типом. Выделение и изучение этнической культуры калмыков на современном этапе с учетом субэтнических различий необходимо, так как Э. П. Бакаева считает: «игнорирование субэтнических различий затрудняет использование ряда источников и научной литературы из-за отсутствия ссылок на субэтническую идентичность информантов либо объектов антропологического обследования. При этом в процессе полевой работы выявляется сохранность субэтнических групп со специфическими характеристиками» (Бакаева, 2010: 55).

Принадлежащие соседней группе территории воспринимаются у калмыков как «чужое» пространство, за которым существует схожий, но «иной» мир. На свадьбе представители сторон проникают в освоенное пространство друг друга, что сопряжено с обязательным выполнением различ- 
ных ритуалов и обрядов, которые должны стабилизировать вертикальное и горизонтальное членение пространств, вызванных дизъюнкцией и внедрением новых членов.

Цель статьи - рассмотрение современных представлений об освоенном пространстве и взаимосвязи их с особенностями в свадебных обрядах у представителей различных субэтнических групп калмыков. Данная тема не была ранее предметом специального исследования. Исследователи лишь указывали на существование общих различий в проведении обрядов календарного и жизненного циклов у представителей различных субэтнических групп, выделяя только отдельные ритуалы и обряды.

В работе применяется синхронно-диахронный, сравнительно-функциональный, сравнительно-сопоставительный и семантический подходы.

Источниками, использованными при проведении исследования стали полевые материалы автора по свадебной обрядности, собранные в 2008-2010 гг., которые были использованы при реконструкции некоторых этапов традиционной калмыцкой свадьбы и описания структурных элементов современной свадьбы (Шараева, 2010, 2011), а также собранные в 2018-2019 гг. Кроме этого, автор опиралась на описания традиционной свадебной обрядности калмыков, которые есть в работах путешественников, миссионеров и исследователей быта калмыков, побывавших в Калмыцкой степи, начиная с XVII-XIX вв. В контексте рассматриваемой темы наибольший интерес представляют труды И. А. Житецкого, который основываясь на собственных наблюдениях достаточно подробно описал структуру свадебной обрядности, отметив в ней субэтнические различия у торгутов и дербетов (Житецкий, 1893). П.И.Небольсин, посетивший в середине XIX века Хошеутовский улус, указал на наличие матрилокальных черт проводимой свадьбы: отсутствие смотрин жениха как этапа в досвадебном цикле, доставление специальной кибитки для молодых в хотон невесты, проведение бракосочетания, обрядов вхождения в новую семью и свадебного пира на стороне невесты и т. д. (Небольсин, 1852). В серии статей И. В. Бентковского о жизни калмыков была подробна рассмотрена свадебная обрядность калмыков Большедербетовского улуса (Бентковский,1869).

Описания свадебной обрядности калмыков, составленные исследователями во второй половине XX в., касаются преимущественно форм семьи и брака калмыков в XIX в., основных свадебных ритуалов и обрядов традиционного свадебного комплекса. Это работы У.Э.Эрдниева (Эрдниев, 1970 , 1985), К. Э. Эрендженова (Эрендженов, 1980, 1985), Д. Д. Шалхакова (Шалхаков, 1982), Э. П. Бакаевой и Э.-Б. М. Гучиновой (Бакаева, Гучинова, 1989). В исследованиях Е. Э. Хабуновой, традиционная калмыцкая свадебная обрядность рассмотрена в контексте обрядовой поэзии и эпической традиции (Хабунова, 1998, 2005, 2006). М. М. Батмаев формы семьи и брака в XVII-XVIII вв. рассмотрел на обширном архивном материале о свадьбе калмыков (Батмаев, 2008). Вместе с тем, пространственные представления у калмыков, их значение в свадебной обрядности не затрагивались в вышеуказанных работах, несмотря на наличие отдельных работ о пространстве в калмыцкой культуре, в которых, в свою очередь, не рассматривались вопросы взаимосвязи со свадебным комплексом калмыков (Пюрвеев, 1975; Бакаева, Сангаджиев, 2005).

\section{«Наша сноха из соседнего улуса»}

У калмыков к началу XX века заключение брака имело несколько форм: брак по сватовству, брак похищением, левират ${ }^{1}$, сорорат ${ }^{2}$, колыбельный сговор ${ }^{3}$. Наиболее распространенным был брак по сватовству. При заключении брака соблюдалась строгая патрилинейная экзогамия, брак между родственниками по отцовской линии запрещался до седьмого или девятого поколения. Поэтому невест старались выбирать либо из отдаленных хотонов, где проживало небольшое количество дальних родственников, либо из других субэтнических групп, отправляясь для поиска невесты в соседние улусы. Различные исторические, социальные, экономические и культурные изменения, происходившие в жизни калмыцкого этноса на протяжении XX века, значительно повлияли на свадебную обрядность: исчезли некоторые этапы предсвадебного цикла, например, смотрины жениха, изготовление внутрен-

\footnotetext{
1 Левират - обычай, по которому вдова выходила замуж за деверя. У калмыков такая форма брака была распространенной до начала XX века, так как дети, после смерти отца, должны были оставаться в его роду.

${ }^{2}$ Сорорат - обычай, по которому мужчина вступает в брак с сестрой жены, после ее смерти. У калмыков такая форма брака практиковалась при наличии малолетних детей.

${ }^{3}$ Колыбельный сговор - обычай помолвки младенцев их родителями. Такая форма брака практиковалась у калмыков до конца XIX века, но не была распространенной вследствие различных причин, начиная с возникновения разногласий между родителями обрученных детей до изменения социального и имущественного положения.
} 
него убранства кочевого жилища, сократились и трансформировались собственно свадебные этапы и обряды, появились новые, отражающие социальную значимость советской семьи и т. д. Вместе с тем, традиционные свадебные обряды сохраняли свои позиции, оставаясь основой социальной регуляции, что позволило сохранить исторический пласт свадебной обрядности к началу XXI века. Остался без изменений и подход в выборе брачного партнера с соблюдением экзогамности брака, будущие сваты также обращают внимание на родовую, этническую и территориальную принадлежность друг друга.

У калмыков к XXI веку сложилась форма восприятия пространства, сочетающая в себе древние номадические знания о пространстве и современные территориальные идентичности, которые, как принято считать, трансформируются в течение всего жизненного цикла личности. Ответ большинства современных калмыков на вопрос об их идентичности зависим от этнической принадлежности собеседника и темы беседы: если калмык или калмычка встретит калмыка, то укажет свою внутриэтническую принадлежность (субэтнос, этническую группу, малую патронимическую группу), если человека другой национальности, то, в первую очередь, этническую принадлежность. Согласно выводам А. Б. Имкеновой, уровни идентичности, которые важны калмыкам, выстраиваются следующим образом: этническая принадлежность, затем республиканская, религиозная и российская (Имкенова, 1999: 62). Наличие множественности идентичностей или обладание смешанной идентичностью является характерной особенностью российских народов, в том числе калмыков как «русских» монголов (Попков, Четырева, 2009: 81), при этом для жителей национальной республики и представителей определенного этноса «этническая идентичность сильнее» (Дробижева, 2014: 76).

При рассмотрении этнического состава калмыков необходимо учитывать взаимосвязь этнического и административного делений, тесно переплетенных между собой. В традиционном калмыцком обществе каждая из номинаций - улус (улс), аймак (әәмг), анги (әңг), хотон (хотн) - были многосоставными и в этническом, и в административном отношениях. Кроме того, термином «улус» у калмыков обозначаются и административная единица, и население, люди. «Улус» в значении самой крупной номинации представлял собой «субэтнос... с определенной социально-политической организацией...обладали этническим самосознанием и самоназванием-этнонимом» (Батмаев, 2002: 112). Поэтому «более мелкие этнические образования... этнические группы... входя в состав то ли торгутов, то ли дербетов и хошутов, осознавали себя этнически в первую очередь именно членами того субэтноса, в составе которого они находились и развивались экономически, политически, культурно и т. д.» (там же:117).

Улус состоял из нескольких отоков (отг), а те в свою очередь, из аймаков (әәмг), которые были разными по численности и территории кочевья, при этом «все жители аймака считались этнически родственной группой и оказывали друг другу взаимную поддержку или помощь» (Авляев, 2002: 42). Аймаки делились на анги (калм. әңг, букв. - часть), а те на хотоны (хотн) - поселение родовой группы ${ }^{1}$.

Территория кочевья улуса маркировалась также термином «нутук» (нутг), которое в культурах монгольских народов имеет более широкое значение, обозначая, в первую очередь, родную землю, родину. В ханский период калмыцкие улусы кочевали по всей территории ханства. Дербетские улусы кочевали по определенным маршрутам в западном направлении, а хошутские и торгутские - повосточному. Перекочевки осуществлялись в меридиональном направлении, «весеннее-летний сезон калмыки проводили на левой стороне Волги, а зимовали на правобережье и левобережье в приморских районах» (Трансграничная культура..., 2016: 99).

После ухода трех четвертей калмыцких улусов в Джунгарию и ликвидации ханства в 1771 г.территория кочевий резко сократилась, и началось формирование новой административной системы. Основу ее составили как старые улусы, так и новые улусные единицы, возникавшие или из выделившихся частей старых улусов или из разрозненных остатков уведенных наместником улусов» (История Калмыкии ..., 2009: 444). На начало XX века кочевья калмыков делились на следующие улусы: Малодербетовский ${ }^{2}$ Манычский ${ }^{3}$, Икицохуровский, Багацохуровский, Харахусовский, Хошеутовский, Эркетеновский и Яндыко-Мочажный. Они подразделялись на 38 аймаков (Борисенко, Убушиева, 2000: 83).

В 1920 г. была создана Калмыцкая автономная область, которая объединила близлежащие территории расселения калмыков Астраханской и Ставропольской губернии. Группы калмыков, которые

\footnotetext{
${ }^{1}$ Позднее - поселение этнотерриториальной группы.

${ }^{2}$ B конце XVIII в.Дербетовский улус в результате наследственных споров был разделен на два улуса - Малодербетовский и Большедербетовский. В названии отразилось численное соотношение населения улусов. В административном отношении Большедербетовский улус находился в Ставропольской губернии, а Малодербетовский - в Астраханской губернии.

${ }^{3}$ Выделился из южной части Малодербетовского улуса.
} 
проживали в других регионах, стали переселяться на территорию автономии, в основном, в Большедербетовский улус ${ }^{1}$. Там они создавали свои отдельные поселения. При этом значительная часть донских калмыков отказалась переселяться в Калмыкию, поэтому для них был образован Калмыцкий национальный район в составе Ростовской области. Последние преобразования в административном устройстве Калмыцкой АССР были произведены в 1938 году², когда были сформированы 13 улусов: Сарпинский, Малодербетовский, Кетченеровский, Приютненский, Черноземельский, Долбанский, Лаганский, Юстинский, Приволжский, Западный, Яшалтинский, Троицкий и Улан-хольский (Борисенко, Убушиева, 2000: 94).

В 1943 г. Калмыцкая АССР и Калмыцкий район были ликвидированы, а калмыки высланы в Сибирь. В 1957 г., после ХХ съезда КПСС, калмыцкая автономия была восстановлена, и калмыки смогли вернуться на родину. При этом они возвращались, как правило, в те места, где проживали до выселения. Однако было два исключения. Во-первых, не был восстановлен Калмыцкий район Ростовской области, вовторых, территория Приволжского и Долбанского улусов при восстановлении автономии осталась в составе Астраханской области: территориальные споры о ней продолжаются до сих пор (Гунаев, 2019: 207-219). Под давлением различных обстоятельств значительная часть калмыков этих районов была вынуждена переселяться в Калмыкию.

Таким образом, территория этнического расселения калмыков после 1957 г. за этими двумя исключениями в целом соответствовала территории, сложившейся еще в XIX в. В настоящее время дербеты проживают в: Городовиковском, Яшалтинском, Приютненском, Ики-Бурульском, Целинном, Кетченеровском, Сарпинским, Малодербетовском, частично Октябрьском районах. Торгуты проживают в Яшкульском, Черноземельском, Юстинском, Лаганском, частично Октябрьском районах. Бузавы, переселившиеся в Калмыкию в 1920-х гг., по-прежнему проживают в Городовиковском районе. Немногочисленные группы хошутов точечно проживают в нескольких селах центральной и восточной части Калмыкии

\section{«Моя земля»}

В сознании современных калмыков территории бывших улусов и кочевавших внутри них аймаков и хотонов воспринимаются «своей» землей для представителей определенной субэтнической группы, например, торhуда һазр (торгутская земля; территория, где проживают торгуты), дөрвүдә һaзp (дербетская земля; территория, где проживают дербеты), бузавнр бәддг һазр (земля, где живут бузавы), хошуда hазр (территория, где проживают хошуты), являются значимым локальным пространством на территории республики.

В нашем исследовании понятие «локальное пространство» применяется также для описания множественности концентрических кругов (территория бывшего улуса, внутри нее - территория анги, внутри нее - территория аймака, внутри нее - территория хотона). Каждый из этих кругов и движение в них к центру - это понимание человеком своей территории, которое позволяет вникнуть в понятие «земля предков» и оно отличное для представителей субэтнических групп (этнических групп, патрилинейных групп) калмыков. Локальное освоенное пространство у калмыков многосоставное, состоит из кругов, находящихся внутри другого круга, а центром освоенного локуса в них - место конкретного проживания человека, его родственного социума. Для традиционного калмыцкого общества «освоенное хозяйственное пространство налагалось на родовое пространство, совпадало с ним. Здесь жили предки, сюда возвращались после долгих кочевок, после набегов на чужую землю. По мере удаления от родового пространства оно становилось расплывчатым, неконкретным» (Жуковская, 2002: 31).

Концепт мини hазр (букв. 'моя земля') у калмыков включает принадлежность по этническому и этнотерриториальному принципу, например, мадн нег әәмгә, нег төрлә улс (букв. 'мы люди одного аймака,

${ }^{1}$ В ходе феодальных междоусобиц ряд калмыцких родов и групп покинули территорию ханства и присоединились к различным казачьим войскам на окраинах Российской империи: Донскому, Терскому, Астраханскому, Уральскому, Ставропольскому (до 1842 г.), Оренбургскому. Также образовался Кумской аймак на территории, прилегающей к реке Куме. Большей частью эти группы ассимилировались и стали сокращаться в численности, за исключением донских калмыков, которых стали называть «юртовыми» или «базовыми» (калм. бузава). На их основе позднее сформировалась современная субэтническая группа бузавов. Ее составили выходцы, в основном, из торгутовских и дербетовских улусов, что нашло отражение в названии станиц, в которых они проживали.

${ }^{2}$ Начиная с образования Калмыцкой автономной области преобразования в административном делении производили в 1920, 1923, 1930, 1935 гг. 
одного рода'), мана нутга күн ('человек из нашего нутуга'), мана улс ('наши люди'), эн һазра күн ('человек, родом из этой местности'), где территория родного кочевья и является местом проживания родного социума. Многие калмыки старшего поколения (от 50 лет и старше) знают границы проживания своего рода по различным маркерам: балкам, дорогам, полям, фермам, водным источникам, столбам и т. д. Они знают представители каких родов проживают рядом и где проходят границы территории их проживания. Для тех, кто родился в поселках (колхозах, совхозах) в 60-е гг. XX века, созданных в местах нахождения хотонов до депортации, пределы бывших кочевий рода воспринимаются родовой территорией - малая родина, мана һазр (наша земля), өвкнрин һазр (земля предков), унсн/төрснһазр (букв. 'место, где упал'; ‘место, где родился').

Для современных молодых калмыков это тоже «земля предков», малая родина их родителей, место, где проживали дедушки и бабушки, близкие родственники. Сейчас уже заметно меньше, в сравнении с концом 1990-х гг., отправляют городских детей в сельскую местность к родственникам в период школьных каникул «для поправления здоровья», оказания посильной помощи в хозяйстве и погружения «в родную среду». Тем не менее, такая поездка воспринималась и воспринимается как «поехать к своим», «домой», «отправить ребенка к своим».

\section{«Свое» - «чужое» пространство}

В ответе на вопрос Кенәхнә күргн/күүкн? (чей жених/невеста? какого рода жених/невеста? откуда будущий зять/сноха?) отражается субэтническая принадлежность будущего зятя/снохи, их этническая группа/род и территориальная принадлежность, ритуальные и обрядовые особенности в свадебном комплексе. В сознании современных калмыков данные в ответе выстраиваются по принципу «свой»«свой», «свой» - «чужой». В отношениях «свой»- «свой», сторона невесты определяет для себя, что в субэтническом отношении - это родственный социум со знакомой территорией проживания, и сходным свадебным обрядовым комплексом, однако, в ритуальном и обрядовом отношении могут иметься различия в зависимости от групповой и родовой принадлежности и локальной территории проживания брачующихся сторон. Описание таких свадеб заключено, чаще всего, в краткой фразе «торгутская/ дербетская/хошутская/бузавская» свадьба. Иначе дело обстоит, если будущие сваты находятся в оппозиции «свой» - «чужой» по этническому и территориальному признакам. Представления о будущей свадьбе и поездке сватов, особенностях проведения свадебных обрядов, базируются на понятии об «инаковости», «чужеродном», «чужом», перемещение в другое пространство.

Согласно традиционному мировоззрению калмыков в канве свадьбы происходит взаимодействие представителей двух противоположных друг другу миров, и каждая сторона воспринимается связанной с «чужим» или «иным» миром по отношению к другой стороне, которое маркируется в калмыцком языке термином хәр һазр (букв. 'чужая земля'). Данное положение архетипично, широко отражено в фольклоре и в обрядовой культуре, в том числе, в действиях участников свадьбы.

По мнению А. К. Байбурина, действия сторон на свадьбе, разворачивающиеся в горизонтальном пространстве, «...имеют ярко выраженный сюжетный характер, так как их главные персонажи пересекают границы миров. ... На языке пространственных отношений (в горизонтальном плане) необходимость совершения ритуала вызывается нарушением принципа однородности взаимодействующих сфер (свой, либо чужой). В одном случае чужие оказываются среди своих, в другом - свои среди чужих. Цель ритуала - восстановить нарушенный порядок и укрепить границы между контактирующими мирами» (Байбурин, 1993: 190). В пространственной ориентации у калмыков четырехстороннее деление охватывает реальное горизонтальное пространство по четырем сторонам света: ар үзг (букв. 'задняя сторона') - север, өмн үзг (букв. 'передняя сторона') - юг, барун үзг, нарн суух үзг (букв. 'правая сторона', 'сторона, где солнце садится') - запад, зүн үзг, нарн һарх үзг, дорд ұзг (букв. 'левая сторона', 'сторона, где восходит солнце', ‘нижняя сторона') - восток. В контексте свадьбы определяют по сторонам света исходные и конечные точки движения свадебной делегации.

По мнению исследователей, пространство в мировоззрении тюрко-монгольских народов «конечно, замкнуто», так как «беспредельный мир - мир без границ и лишенный меры - это хаос, который не способно освоить мышление человека» (Пространство ..., 2008: 39). Не вдаваясь в семантику базовых понятий о четырех сторонах света у тюрко-монгольских народов, отметим только выделение частей света у калмыков во взаимосвязи с родным пространством той или иной группы. Так, например, термином ap hазра улс (букв. 'люди северной стороны'), маркируют территории проживания дербетов Малодербетовского района, находящиеся на севере республики, ближе к границе с Волгоградской областью. Этим же термином называют представителей этнических групп, территории проживания 
которых, в 20-е гг. XX века вошли в состав Царицынской губернии Нижне-Волжской области (теперь этот район входит в состав Волгоградской области). Говоря «дербеты же на севере живут», имеют виду только ту часть дербетов, которая составляла население Малодербетовского улуса в прошлом. Тех дербетов, которые проживали в Большедербетовском улусе (ныне это Городовиковский и Яшалтинский районы) часто обозначают термином «другие дербеты», «с тех краев», «дербеты с бузавской стороны», так как в сознании современных калмыков чаще всего все жители этих районов связываются с представителями субэтнической группы бузавов, проживающих в западной части республики. В настоящее время считается, что дербеты проживают в северных, центральных и частично в западных частях республики.

Чтобы указать на территорию проживания представителей субэтнической группы торгутов, чаще всего, говорят хар һазра улс (букв. 'люди черной земли'). В данном случае отсылка идет к местонахождению Черных земель - уникального биосферного заповедника в Калмыкии (Черноземельский и Яшкульский районы), земли которого долгое время калмыки использовали в качестве совместного зимнего пастбища для скота из-за отсутствия снежного покрова. Кроме того, существует условное «пространственное» разделение торгутов по наиболее восточному положению - «сухопутные» или «водные» - по расположению крупной водной артерии реки Волга и побережья Каспийского моря. Так, например, У. Д. Душан в описании Эркетеневского улуса ${ }^{1}$ в начале XX века делит его на степную и мочажную: «Эркетеневский улус занимал южную и юго-восточную часть Калмыцкой степи...улус делился на две части: на мочажную и степную...в степной части - ближе к Икицохуровскому улусу, местность становилась более или менее ровной, ... вся мочажная часть улуса протяжением с востока на запад километров 30, а с юга на север около 60 км, буквально была изрезана протоками, речками, ильменями, озерками различной величины и глубины, берега которых заросли густыми труднопроходимыми камышами...» (Душан, 1973: 31-37). Кроме того, по отношению к прикаспийским территориям существует представление о меридиональном движении: подниматься вверх по течению реки Волга означает «двигаться на север», а спускаться по реке - «двигаться на юг». Отношение к водному источнику как к особому объекту освоенного пространства было характерно и для калмыков, проживавших и на Дону: те, кто жил на левом берегу Дона проживали на «внутренней стороне» - дота haзp, а на правобережье - «люди внешней стороны» hаза һазр (Бакаева, 2009: 299).

В канве свадебных обрядов у калмыков важное значение имеет и трехчастное деление пространства по вертикали, связанное с представлениями о трех сакральных мирах: верхний мир - мир небожителей; средний мир - мир людей; нижний мир - мир хтонических существ, знаковость и акцентирование к которым затрагивает сферу мировоззрения и картины мира, сходных с тюрко-монгольских народами, и обрядовой культуры у калмыков. Также оно связано с представлениями о предках-покровителях жениха и невесты. У калмыков существует представление, что предки, захороненные на территории проживания родного социума, становятся в дальнейшем покровителями ээж-аавин заян сәкүсн, дарующими потомкам благополучие, чадородие; они постоянно оказывают покровительство и помощь в различных жизненных ситуациях. И в традиционном обществе и сегодня у калмыков коллективное сознание отражает единение предков и потомков, сакрального и профанного миров, поэтому «строя свои взаимоотношения с миром, традиционное общество проецировало их на временную ось. Гарантией существования рода было непрерывное единство предков и потомков, умерших и живых» (Сагалаев, Октябрьская,1990: 28). Данные представления не утратили своего значения и актуальности.

Еще один значимый момент в восприятии пространства и по горизонтали, и по вертикали в свадебной обрядности у калмыков связан с пересечением определенной местности, которая имеет локальных хозяев, духов-местности эзн/эздүд, эн усн-һазрин эзн/эздүд (букв. 'хозяева этой воды-земли'). Как покровители местности они относятся к высшему миру, но их влияние и воздействие распространяется на горизонтальную поверхность определенного пространства: родного кочевья в прошлом и территории проживания в настоящем отдельно взятого родственного социума.

В свадебной обрядности калмыков, отправляясь за невестой, члены свадебного «поезда», выстраиваемого из машин, принадлежащих родным и друзьям жениха, заранее рассчитывают маршрут, выбирая, по какой дороге будут передвигаться, время прибытия и отъезда. Выезжают в первой половине (в промежутке между 8 и 9 часами) дня, непременно сделав круг по направлению движения солнца вокруг дома жениха; они должны вернуться домой до начала времени «заката солнца», примерно с 16 часов дня. Если дорога к дому невесты длинна и длительна по времени, например, поездка из Лаганского района

${ }^{1}$ Бывший ханский улус. В этническом отношении представлен представителями субэтнической группы торгутов. 
на востоке республики в Малодербетовский на севере, или Городовиковский на западе протяженностью более 300-400 км, то выезжают в предрассветное время или на рассвете. При продвижении на такие большие расстояния, члены свадебной делегации жениха остаются ночевать на стороне невесты, чтобы с наступлением рассвета отправиться в обратный путь. Существует правило: движущийся свадебный «поезд» не останавливают; его участники не берут попутчиков.

Отъезду свадебного «поезда» жениха за невестой предшествует обязательное совместное чаепитие уезжающих и остающихся родственников с произнесением благопожеланий для скорейшего возвращения после выполнения возложенных обязанностей, совершается подношение духам местности в виде выбрасывания цаһан-улан мөңгн (белой и красной монет) за пределы дворовой территории и кропления молоком перед машинами с пожеланием «белой дороги» перед отъездом от дома жениха. На границе выезда с родной территории (границ территории проживания группы, рода) совершается такое же подношение духам местности. При въезде в пределы района, где проживает невеста, а затем и населенного пункта, совершаются подношения с целью временного благополучного нахождения в чужой местности, чем задабриваются духи-хозяева местности.

По традиции приехавший свадебный «поезд» жениха сначала должен объехать посолонь (по ходу движения солнца) вокруг населенного пункта, затем - остановиться на некотором расстоянии от дома родителей невесты. Глава свадебной делегации ахлач жениха отправляется в дом родителей невесты для получения разрешения войти от ее родственников. Вместе с тем, приехавшие гости не могут сразу после возвращения к ним ахлач войти в дом родителей невесты. Они должны приблизиться к дому, выложить все привезенное угощение за пределами двора и только после его проверки родными невесты войти во двор и далее - в дом, внося свое угощение. В городских условиях члены свадебного кортежа жениха осуществляют объезд вокруг микрорайона или близлежащих домов, привезенное угощение выставляют перед входом в подъезд. Таким образом, движение членов свадебного «поезда» жениха со своей территории на сторону невесты сопряжено с выходом за границы «своего» пространства и вхождением в «чужие границы», испрашивания покровительства духов-хозяев местности как своих, так и чужих на всем протяжении своего пути. Аналогичные действия совершают родственники невесты күргұлин улс, которые едут вслед за невестой на сторону жениха, находятся там некоторое время и возвращаются домой.

Для жениха, как будущего зятя, важным является выполнение всех требований родственников невесты на свадьбе. Соблюдение всех ритуальных и обрядовых действий, прохождение обрядов приобщения им на стороне невесты указывает, что он станет «своим», знающим традиции своего родственного сообщества и почтительно относящимся к традициям и обычаям, принятым на стороне невесты.

Возвращение свадебной делегации жениха с невестой домой также маркируется этапами пересечения границ территорий, но уже «своих», и возвращением под покровительство «своих» духов-хозяев местности. Так, возвращающуюся свадебную делегацию жениха встречают вестовые - родственники жениха тосул улс (букв. 'встречающие люди'). Встреча проходит на границе «своей» территории, поэтому участники совместно совершают подношения различным духам-хозяева местности, угощаются сами: моделируется ситуация «коммуникации людей и духов» (Неманова, 2019: 247). В условиях традиционного быта после угощения устраивались скачки, победитель которой получал из рук девушки белый платок, маркирующий достижение пределов родной территории и ее центра. В городских условиях тосул улс встречают участников свадебной делегации возле дома или подъезда. Таким образом, в современной свадебной обрядности калмыков движение участников свадебного кортежа жениха - это поэтапный выход за пределы границ «своего» пространства, имеющего форму концентрических кругов, временное внедрение в такое же, но «чужое» пространство, и возвращение обратно, что указывает на сохранение традиционных представлений о пределах кочевий родного социума в современных реалиях. По мнению Н. Л. Жуковской, у кочевников жилье «...некий центр, вокруг которого концентрическими кругами располагался весь остальной мир. Юрта - центральный круг, хозяйственное пространство вокруг нее - второй круг, за пределами коновязи - третий (до его условных границ часто провожали гостей) и т. д. это достаточно универсальный принцип осмысления себя, своего жилья, своего места во вселенной, характерный для многих народов земного шара, принцип, в котором слились воедино реальное и мифологическое освоение мира...границы последнего круга были пограничной линией территории рода... освоенным, сакральным считалось все пространство, заключенное внутри внешнего круга, будь то айл, хотон или орда, а сам внешний круг был границей мира своего или чужого...» (Жуковская, 2002: 26). 
Восприятие внутреннего пространства жилища у калмыков-кочевников как одомашненного, освоенного (космос/микрокосмос) противопоставлялось неосвоенному внешнему миру (хаосу/макрокосмосу), а позднее, с переходом на оседлый образ жизни - перенесено на пространство современного жилища и прилегающей территории. Поэтому нахождение и размещение участников свадебного застолья (обычно это самая большая комната в доме, которая отождествляется с единым пространством кочевого жилища) в пространстве современного дома сохраняет пространственносемантический код традиционной культуры калмыцкого этноса, в котором важным является соотношение различных понятий в двоичной системе горизонтального (правый - левый, мужской женский, западный - восточный, почетный - непочетный, верхний - нижний) и троичной системе вертикального членения пространства (верхний - средний - нижний). Также, как в кочевом жилище, пространство внутри комнаты, где сидят гости, делится на сакральную и профанную зоны, значение которых связано с этнической картиной мира, гендерным делением и социальными характеристиками, противопоставлена околодверному пространству и двери как межевой зоне с внешним миром; внутри такого пространства движение осуществляется по ходу движения солнца. Поэтому, прибывших гостей принято располагать в правой почетной половине (как и прежде стороны определяются по нахождению человека в глубине жилища лицом к двери). Расположение участников застолья на свадьбе, когда проявляются все семантические категории мировоззрения и восприятия пространства «...подчинено правилу: по обеим сторонам жилища присутствующие размещаются согласно гендерному делению, а в каждой линии сидящих - по нисходящей по возрасту и статусу от сакральной части» (Трансграничная культура ..., 2016: 142).

На разницу в обрядовой сфере в зависимости от субэтнической принадлежности (внутри нее групповой или родовой) отмечали многие исследователи традиционного быта калмыков, например, И. А. Житецкий в описании свадебного комплекса у калмыков в XIX в. указал на различия между торгутским и дербетским вариантами (Житецкий, 1893), а П. И. Небольсин подробно описал свадьбу у хошутов, выделяя матрилокальные черты (Небольсин, 1852). При проведении современной свадьбы калмыки определяют обрядовые особенности в зависимости и от этнической принадлежности, и от территориальной. Например, для дербетов характерно подношение белых ритуальных штанов для матери жениха, у торгутов - использование белого платка, закрывающего лицо невесты вместо фаты во время вывода ее из родительского дома; доставление семи обязательных лепешек для подношения на алтаре в доме родителей невесты у бузавов. Кроме того, считается, что среди «водных» торгутов у представителей локальных этнических групп багутов и цаатанов распространен обряд жертвоприношения огню жертвенной овцой, которую живой привозит на свадьбе сторона жениха. Торгуты «степные» и некоторые рода у хошутов, кроме живого барана, привозят тушу свадебного барана в сыром виде или только правую переднюю ногу животного. Для дербетов такое оформление ритуальной туши неприемлемо: нельзя доставлять на свадьбу мясо «с кровью». Отправляясь за невестой, они везут сватам живую овцу и тушу вареного барана, части которого складывают в анатомическом порядке. Как говорят калмыки: hазр болһн эврә йоста (букв. ‘в каждой местности свои традиции’).

Представители брачующихся сторон до начала свадебных этапов стараются уточнить имеющиеся сведения и договориться о соблюдении обязательных для одной из сторон. Например, договариваются, что прощальные обряды перед увозом невесты будут совершаться согласно устоявшимся традициям в родном сообществе невесты, а ее увоз и последующие действия на стороне жениха - согласно уже их обычаям. Во избежание недоразумений и споров сторона невесты может выдвинуть требование, чтобы во время прибытия свадебного «поезда» жениха были доставлены все знаковые атрибуты и продукты, которые имеют большое значение для представителей стороны невесты: «К нам приезжайте так, как принято у нас». Либо идут на уступку: «Приезжайте так, как у вас принято, мы вас встретим, но на нашей территории все будет проводиться по-нашему». «Законники» (йосарн бәәдг - букв. 'живущие по своим законам’) - так называют современных калмыков, соблюдающих весь свадебный комплекс, характерный для представителей той или иной группы, которые детально воспроизводят и понимают значение всех действий. К ним относят жителей тех мест, где сохраняется знание национального языка, культурных особенностей, в том числе в обрядовой сфере. Так, среди представителей субэтнической группы дербетов «законниками» считают жителей п. Кетченеры, п. Ергенинский, п. Тугтун; у торгутов - п. Чилгир, г. Лагань; у хошутов - п. Сарпа, п. Эвдг; у бузавов - г. Городовиковск. Таким образом, выстраивая взаимосвязь между представителями той или иной субэтнической группы (уже представителями этнических групп и родов) и территорий их проживания определяют особенности в свадебных обрядовых комплексах. Таким образом, учитывая взаимосвязь между представителями той 
или иной субэтнической группы (уже - представителями этнических групп и родов) и территорией их проживания определяют особенности в свадебных обрядовых комплексах.

Для невесты перемещение от родного дома до дома жениха сопряжено с этапом изъятия ее и переходом, в том числе на сакральном уровне, из «своего» (родного пространства) в «чужое» через различные по времени этапы. У. Д. Душаном был зафиксирован в начале XX века образец фольклора, в котором мать выходящей замуж девушки переживает не только об ее будущей жизни, но и питании дочери в новой семье с непривычным укладом: «Милая моя, ты выросшая, питаясь привычным тебе мясом белуги и осетра, ты будешь теперь питаться этим невкусным, водянистым мясом барана. Ты, привыкшая сидеть на корме лодки и направлять ее рулем куда захочешь, теперь будешь управлять головой двухмачтового (верблюда)» (Душан, 1973: 45).

После прикосновения к ней главы свадебного поезда ахлач в доме ее родителей, она считается «чужой», поэтому ее родные начинают проведение обрядов отделения ее от родного сообщества, приравненные в семантическом значении с прощальными обрядами похоронной обрядности. Введение ее в новое, но еще «чужое» пространство жилища жениха происходит через серию знаковых обрядов, соотносимых с обрядами родильного цикла, фиксирующих ее появление как нового члена в пространстве жилища и прилегающей территории, всего родного пространства жениха. Так, невеста совершает поклоны на пороге жилища родителей жениха, после первого шага невесты внутри жилища ей мажут лоб сливочным маслом и дают в руки кусочки жира для бросания в семейный очаг, локализация которого в современных условиях перемещена в/на газовую плиту, с помощью старших снох и свекрови она совершает подношение у семейного алтаря. Таким образом, ею преодолевается порог как межевая зона, а фиксация на новом месте как нового члена теперь уже родного для нее сообщества и территории, происходит через совершение обрядов приобщения и подношения внутри жилого пространства как центра освоенного пространства согласно существующим обычаям у жениха. Именно соблюдение обычаев, характерных для конкретной группы в определенной местности, определяет ее дальнейшую жизнь и отношение новых родственников: «Все соблюла как надо, значит и по-нашему научится жить». Так, например, у дербетов практикуется совершение обряда поклонения невесты на пороге жилища не только в доме родителей жениха, но и его братьев и старших родственников. У торгутов для окончательного «внедрения» невесты в цикле свадебных обрядов совершается обязательное жертвоприношение огню внутри дома родителей жениха (=сакральный центр пространства родного сообщества). Для этого ей вручают правую ногу жертвенного животного, которым она совершает троекратные удары по полу, фиксируя свое «новое» местонахождение.

Вместе с тем, нельзя не согласиться с мнением М. М. Содномпиловой, что вышедшая замуж женщина долгое время идентифицирует себя по родовой принадлежности отца, оставаясь все же «чужой» и для родных мужа, и для близких родных. Только к глубокой старости (по завершении репродуктивного возраста) она отождествляет себя с родовой принадлежностью мужа (Содномпилова, 2014: 428). «Инаковость» и «чужеродность» ее для членов сообщества мужа долгое время воспринимается посредством участия в общественных мероприятиях, где она должна выполнять поручения и подсобные работы под руководством старших по возрасту и статусу снох группы/рода, которые уже «перешли» на другой образ жизни, соблюдают другую обрядность, стали жить «по местному», прижились и знают обычаи этих мест.

\section{Заключение}

Для калмыков пространство многомерно. И в условиях кочевого быта, и в современных реалиях в восприятии пространства отражается взаимосвязь с сакральными и профанными мирами, его вертикальное и горизонтальное членение. Калмыки, за короткий период перешедшие на оседлый образ жизни, продолжают связывать деление пространства с существовавшим в прошлом улусно-административным делением и этнической идентичностью, формирующим взаимосвязь по географическому признаку и хозяйственно-культурными традициями. Наслоение этих представлений на пространство современной республики позволяет рассмотреть, как участники свадебной обрядности через призму понятий «свое» - «чужое» выстраивают акт коммуникации между двумя сторонами, в котором действия обыгрываются с учетом сложившихся у них традиций. 


\section{СПИСОК ЛИТЕРАТУРЫ}

Авляев, Г. О. (2002) Происхождение калмыцкого народа. 2 изд-е, перераб. и исправл. Элиста: Калмыцкое книжное издательство. 325 с.

Байбурин, А. К. (1993) Ритуал в традиционной культуре. Структурно-семантический анализ восточнославянских обрядов. СПб. : Наука. 239 с.

Бакаева, Э. П. (2009) Речная тематика в верованиях и ритуалах калмыков: древние представления о пространстве и проблема прародины // Материалы Международной научной конференции «Единая Калмыкия в единой России: через века в будущее» (13-18 сентября 2009 г.): в 2-х ч. / отв. ред. Н. Г. Очирова. Элиста : АПП «Джангар». Ч. 1. 445 с. С. 297-301.

Бакаева, Э. П. (2010) «Чьи вы?» (специфика полевой работы в среде калмыков в связи с проблемой самоидентификации) // Этнографическое обозрение. № 3. С. 54-65.

Бакаева, Э. П., Гучинова, Э.-Б. М. (1989) Традиционные представления калмыков о жизненном цикле и их отражение в свадебном обряде // Обычаи и обряды монгольских народов / отв. ред. А. Г. Митиров. Элиста: Калмыцкий научно-исследовательский институт истории, филологии и экономики. 126 с. C. 3-16.

Бакаева, Э. П., Сангаджиев, Ю. И. (2005) Культура жилища: этнические традиции и современные приоритеты у калмыков. Элиста : АПП «Джангар». 196 с.

Батмаев, М. М. (2002) Социально-политический строй и хозяйство калмыков в XVII-XVIII вв. Элиста : АПП «Джангар». 400 с.

Батмаев, М. М. (2008) Семья и брак в традициях калмыков. Элиста : ГУ «Издательский дом «Герел». 256 c.

Бентковский, И. В. (1869) Женщина-калмычка Большедербетовского улуса в физиологическом, религиозном и социальном отношении // Сборник статистических сведений о ставропольской губернии. Ставрополь: Ставропольский статистический комитет. Вып. II. 468 с. С. 147-167.

Борисенко, И. В., Убушиева, С. И. (2000) Очерки исторической географии Калмыкии. 1917 - начало 90-х г. ХХ в. / отв. ред. Ю. О. Оглаев. Элиста: АПП «Джангар». 168 с.

Гунаев, Е. А. (2019) Размежевание территорий с Астраханской областью и возвращение населения в период восстановления автономии Калмыкии в 1957-1958 гг.: административно-управленческий и гуманитарный аспекты // Oriental Studies. № 2. С. 207-219.

Дробижева, Л. М. (2014) Российская, этническая, региональная идентичности: лонгитюдное исследование 1993-2012 годов // Вестник РГНФ. № 2. С. 71-83.

Душан, У. Д. (1973) Историко-этнографические заметки об Эркетеневском улусе Калмыцкой АССР // Этнографические вести. № 3 / отв. ред. Н.Ш. Ташнинова. Элиста : Калмыцкий научно-исследовательский институт языка, литературы и истории при Совете Министров Калмыцкой АССР. 230 с. С. 31-107.

Житецкий, И. А. (1893) Очерки быта астраханских калмыков (этнографические наблюдения 1884-1886 гг.). М. : Типография М. Г. Волчанинова. 87 с.

Жуковская, Н.Л. (2002) Кочевники Монголии: Культура. Традиции. Символика : учебное пособие. М. : Восточная литература. 247 с.: ил.

Имкенова, А. Б. (1999) Этническая идентичность калмыков. Элиста: АПП «Джангар». 91 с.

История Калмыкии с древнейших времен до наших дней (2009): в 3 т. / К. Н. Максимов, Н. Г. Очирова. С. С. Белоусов, У. Б. Очиров и др. Элиста : ГУ «Издательский дом «Герел». Т. 1.846 с.

Небольсин, П. И. (1852) Очерки быта калмыков Хошеутовского улуса. СПб. : Типография Карла Крайя. 192 c.

Неманова, Э. А. (2019) Обрядовый текст и контекст культа Белого старца в культуре монголоязычных народов // Oriental Studies. № 2. С. 245-254.

Попков, Ю. В., Четырова, Л. Б. (2009) Калмыцкая молодежь: ценности «русских» монголов в сравнительной перспективе // Материалы Международной научной конференции «Единая Калмыкия в единой России: через века в будущее» (13-18 сентября 2009г.): в 2-х ч. / отв. ред. Н. Г. Очирова. Элиста: АПП «Джангар». Ч. 1.445 с. С. $80-86$.

Пространство в традиционной культуре монгольских народов (2008) / Б. 3. Нанзатов, Д. А. Николаева, М. М. Содномпилова, О. А. Шагланова. М.: Восточная литература. 341 с.

Пюрвеев, Д. Б. (1975) Архитектура Калмыкии. М. Стройиздат. 190 с.

Содномпилова, М. М. (2014) Чужие для всех: группа «невестки» в концептуальном универсуме монгольского общества // Сибирский сборник-4: Грани социального: антропологические перспективы исследования социальных отношений и культуры / отв. ред. В. Н. Давыдов, Д. В. Арзютов СПб. : Музей антропологии и этнографии им. Петра Великого (Кунсткамера) РАН. 726 с. С.419-431. 
Сагалаев, А. М., Октябрьская, И. В. (1990) Традиционное мировоззрение тюрков Южной Сибири. Знак и ритуал / отв. ред. И. Н. Гемуев. Новосибирск : Наука. 209 с.

Трансграничная культура: очерки сравнительно-сопоставительного исследования традиций западных монголов и калмыков (2016) / Э. П. Бакаева, К. В. Орлова. Д. Н. Музраева и др. Элиста : Калмыцкий научный центр РАН. 456 с., ил.

Хабунова, Е. Э. (1998) Калмыцкая свадебная обрядовая поэзия / отв. ред. В. М. Гацак. Элиста : Калмыцкое книжное издательство. 224 с.

Хабунова, Е. Э. (2005) Очаг. Обряды и обрядовый фольклор жизненного цикла калмыков / отв. ред. А. В. Бадмаев. Элиста : АОР «НПП «Джангар». 206 с., ил.

Хабунова, Е. Э. (2006) Героический эпос «Джангар»: поэтические константы богатырского жизненного цикла (сравнительное изучение национальных версий) / отв. ред. Г. Ц. Пюрбеев. Ростов-на-Дону : Издательство СКНЦ ВШ. 256 с.

Шалхаков, Д. Д. (1982) Семья и брак у калмыков (XIX - начало XX в.) Историко-этнографическое исследование / отв. ред. С. И. Вайнштейн. Элиста : Калмыцкий научно-исследовательский институт истории, филологии и экономики при Совете Министров Калмыцкой АССР. 86 с.

Шараева, Т. И. (2008) Ритуальная «смерть» и «возрождение» невесты в свадебном обряде у калмыков // Материалы Международной научной конференции «Ойраты и калмыки в истории России, Монголии и Китая» (9-14 мая 2007 г.): в 3-х ч. / отв. ред. Н. Г. Очирова. Элиста : Калмыцкий институт гуманитарных исследований. Ч. 3. 165 с. С. 91-95.

Шараева, Т. И. (2009) «Смотрины жениха» в традиционной калмыцкой свадьбе (по литературным данным) // Известия Российского государственного педагогического университета им. А. И. Герцена. № 117. С. 89-94.

Шараева, Т. И. (2018а) «А «плохую» шею мы оставим дома» (о символике шейных позвонков в свадебной обрядности калмыков) // Oriental Studies. № 4. C. 75-85. DOI: 10.22162/2619-0990-2018-38-4-7585

Шараева, Т. И.(2018б) «Когда говоят о свадьбе, то даже и иссохший череп катится» (к вопросу о значении бараньей головы в свадебных обрядах) // Монголоведение. № 2 (13). С. 20-34. DOI: 10.22162/2500-15232018-13-22-37

Шараева, Т. И. (2010) Свадебная обрядность // Калмыки / отв. ред. Э. П. Бакаева, Н. Л. Жуковская / Серия «Народы и культуры». М. : Наука. 568 с. С. 249-270.

Шараева, Т. И. (2011) Обряды жизненного цикла калмыков (XIX - начало XXI в.). Элиста : ЗАОр «НПП «Джангар». 223 с.

Эрдниев, У. Э. (1970) Калмыки (конец XIX - начало XX в.). Историко-этнографические очерки / ред. Г. Г. Стратанович. Элиста : Калмыцкое книжное издательство. 312 с.

Эрдниев, У. Э. (1985) Калмыки. Историко-этнографические очерки / 3-е изд., перераб. и доп. Элиста : Калмыцкое книжное издательство. 282 с., ил.

Эрендженов, К. Э. (1980) Цецн булг [Родник мудрости]. Элиста : Калмыцкое книжное издательство. 188 с. (На калм. яз.)

Эрендженов, К. Э. (1985) Золотой родник: О калмыцком народном творчестве, ремеслах и быте. Элиста : Калмыцкое книжное издательство. 125 с., ил.

Дата поступления: 03.06.2019 г.

\section{REFERENCES}

Avliaev, G. O. (2002) Proiskhozhdenie kalmytskogo naroda [The origin of the Kalmyk people]. 2nd ed. Elista, Kalmytskoe knizhnoe izdatel'stvo. 325 p. (In Russ.)

Baiburin, A. K. (1993) Ritual v traditsionnoi kul'ture. Strukturno-semanticheskii analiz vostochnoslavianskikh obriadov [Ritual in traditional culture. Structural and semantic analysis of East Slavic rites]. St. Petersburg, Nauka. 239 p. (In Russ.)

Bakaeva, E. P. (2009) Rechnaia tematika v verovaniiakh i ritualakh kalmykov: drevnie predstavleniia o prostranstve i problema prarodiny [River themes in the Kalmyk beliefs and rituals: ancient ideas about space and the problem of ancestral homeland]. In: Materialy Mezhdunarodnoi nauchnoi konferentsii «Edinaia Kalmykiia $v$ edinoi Rossii: cherez veka v budushchee» (13-18 sentiabria 2009g.) [United Kalmykia in United Russia: through centuries into the future]. Proceedings of the international conference (Elista, September 13-18, 2009)], ed. by N. G. Ochirova. Elista, APP «Dzhangar». Vol. 1. 445 p. Pp. 297-301. (In Russ.)

Bakaeva, E. P. (2010) «Ch'ivy?» (spetsifika polevoi raboty v srede kalmykov v sviazi s problemoi samoidentifikatsii) [Whose people are you?": Features of fieldwork among Kalmyks in connection with the problem of self-identification)]. Etnograficheskoe obozrenie, no 3, pp. 54-65. (In Russ.) 
Bakaeva, E. P. and Guchinova E.-B. M. (1989) Traditsionnye predstavleniia kalmykov o zhiznennom tsikle i ikh otrazhenie v svadebnom obriade[Traditional Kalmyk views on the life cycle and their reflection in the wedding ceremony]. In: Obychai i obriady mongol'skikh narodov [Customs and rites of the Mongolian peoples], ed. by A. G. Mitirov. Elista, Kalmytskii nauchno-issledovatel'skii institute istorii, filologii i ekonomiki. 126 p. Pp. 3-16. (In Russ.)

Bakaeva, E. P. and Sangadzhiev, Iu. I. (2005) Kul'tura zhilishcha: etnicheskie traditsii i sovremennye prioritety u kalmykov [The culture of dwelling: ethnic traditions and contemporary priorities among Kalmyks]. Elista, APP «Dzhangar». 196 p. (In Russ.)

Batmaev, M. M. (2002) Sotsial'no-politicheskii stroi i khoziaistvo kalmykov v XVII-XVIII vv. [Socio-political system and the economy of the Kalmyks in the 17th-18th centuries]. Elista, APP «Dzhangar». 400 p. (In Russ.)

Batmaev, M. M. (2008) Sem'ia i brak $v$ traditsiiakh kalmykov [Family and marriage in the tradition of the Kalmyks]. Elista, GU «Izdatel'skiidom «Gerel». 256 p. (In Russ.)

Bentkovskii, I. V. (1869) Zhenshchina-kalmychka Bol'shederbetovskogo ulusa v fiziologicheskom, religioznom i sotsial'nom otnoshenii [The Kalmyk woman of the Bolshederbetovsky ulus in physiological, religious and social terms]. In: Sbornik statisticheskikh svedenii o stavropol'skoi gubernii [A collection of statistical information about the Stavropol province]. Stavropol', Stavropol'skii statisticheskii komitet. Vol. II. 468 p. Pp. $147-167$. (In Russ.)

Borisenko, I. V. and Ubushieva, S. I. (2000) Ocherki istoricheskoi geografii Kalmykii. 1917 - nachalo 90-kh g. XX v. [Essays on the historical geography of Kalmykia from 1917 to the beginning of the 1990s]. Elista, APP «Dzhangar». 168 p. (In Russ.)

Gunaev, E. A. (2019) Razmezhevanie territorii s Astrahanskoi oblastiu I vozvrashenie naseleniya v period vosstanovleniya avtonomii Kalmykii v 1957-1958 gg: administrativno-upravlencheskii I gumanitarnii aspekti [The 1957-1958 Reestablishment of Kalmykia's Autonomy: division of territories with Astrakhan Oblast and return of the Native population. administrative and humanitarian aspects]. Oriental Studies, no. 2, pp. $207-219$. (In Russ.)

Drobizheva, L. M. (2014) Rossiiskaia, etnicheskaia, regional'naia identichnosti: longitiudnoe issledovanie 1993-2012 godov [Russian, ethnic, and regional identity: a longitudinal study]. Vestnik RGNF, no 2, pp. 71-83. (In Russ.)

Dushan, U. D. (1973) Istoriko-etnograficheskie zametki ob Erketenevskom uluse Kalmytskoi ASSR [Historical and ethnographic notes on Erketenevsky ulus of the Kalmyk ASSR]. In: Etnograficheskie vesti [Ethnographic news], no. 3, ed. by N. Sh. Tashninova. Elista, Kalmytskii nauchno-issledovatel'skii institute iazyka, literaturyi i istorii pri Sovete Ministrov Kalmytskoi ASSR. 230 p. Pp. 31-107. (In Russ.)

Zhitetskii, I. A. (1893) Ocherki byta astrakhanskikh kalmykov (etnograficheskie nabliudeniia 1884-1886 gg.) [Essays on the life of the Astrakhan Kalmyks: Ethnographic observations made in 1884-1886]. Moscow, tipografiia M. G. Volchaninova. 87 p. (In Russ.)

Zhukovskaia, N. L. (2002) Kochevniki Mongolii: Kul'tura. Traditsii. Simvolika: uchebnoe posobie [Nomads of Mongolia: Culture. Traditions. Symbolism: A study guide]. Moscow, Vostochnaia literatura. 247 p. (In Rus.)

Imkenova, A. B. (1999) Etnicheskaia identichnost' kalmykov [Ethnic identity of the Kalmyks]. Elista, APP «Dzhangar». 91 p. (In Russ.)

Istoriia Kalmykii s drevneishikh vremen do nashikh dnei [A history of Kalmykia from ancient times to the present day] (2009), ed. by K. N. Maksimov, N. G. Ochirova. S. S. Belousov, U. B. Ochirov et al. Elista, GU «Izdatel'skiidom «Gerel». Vol. 1. 846 p. (In Russ.)

Nebol'sin, P. I. (1852) Ocherki byta kalmykov Khosheutovskogo ulusa [Essays on the Kalmyk life in Khosheutov ulus]. St. Petersburg, Tipografiia Karla Kraiia. 192 p. (In Russ.)

Nemanova E. A. (2019) Obryadovii tekst i kontekst kulta Belogo startsa v culture mongoloyazichnyx narodov [A Cult of the White Old Man in Mongolic Cultures: the Ritual Text and Context].Oriental Studies, no 2, pp. 245-254. (In Russ.)

Popkov, Iu. V. and Chetyrova, L. B. (2009) Kalmytskaia molodezh': tsennosti «russkikh» mongolov v sravnitel'noi perspective [Kalmyk youth: values of the "Russian" Mongols in a comparative perspective]. In: Materialy Mezhdunarodnoi nauchnoi konferentsii «Edinaia Kalmykiia v edinoi Rossii: cherezveka v budushchee» (13-18sentiabria 2009g.) [United Kalmykia in United Russia: through centuries into the future]. Proceedings of the international conference (Elista, September 13-18, 2009)], ed. by N. G. Ochirova. Vol. 1. Elista, APP «Dzhangar». 445 p. Pp. 80-86. (In Russ.)

Prostranstvo $v$ traditsionnoi kul'ture mongol'skikh narodov [Space in the traditional culture of the Mongolian peoples] (2008) / B. Z. Nanzatov, D. A. Nikolaeva, M. M. Sodnompilova and O. A. Shaglanova. Moscow, Vostochnaia literatura. 341 p. (In Russ.)

Piurveev, D. B. (1975) Arkhitektura Kalmykii [Architecture of Kalmykia]. Moscow, Stroiizdat. 190 p. (In Russ.) 
Sodnompilova, M. M. (2014) Chuzhie dlia vsekh: gruppa «nevestki» v kontseptual'nom universume mongol'skogo obshchestva [Alien for all: the "daughter-in-law" group in the conceptual universe of Mongolian society]. In: Sibirskii sbornik-4: Grani sotsial'nogo: antropologicheskie perspektivy issledovaniia sotsial'nykh otnoshenii I kul'tury [Siberian collection 4: The edge of the social: Anthropological perspectives of the study of social relations and culture], ed. by V. N. Davydov, D. V. Arziutov. St. Petersburg, Muzei antropologii I etnografii im. Petra Velikogo (Kunstkamera) RAN. 726 p. Pp. 419-431. (In Russ.)

Sagalaev, A. M. and Oktiabr'skaia, I. V. (1990) Traditsionnoe mirovozzrenie tiurkov Iuzhnoi Sibiri: znak i ritual [The traditional worldview of the Turks of Southern Siberia: The sign and the ritual], ed. by I. N. Gemuev. Novosibirsk, Novosibirskoe otdelenie izdatel'stva «Nauka». 209 p. (In Russ.)

Transgranichnaia kul'tura: ocherki sravnitel'no-sopostavitel'nogo issledovaniia traditsii zapadnykh mongolov I kalmykov [Cross-border culture: A comparative study of the traditions of the Western Mongols and Kalmyks] (2016), ed. by E. P. Bakaeva, K. V. Orlova. D. N. Muzraeva et al. Elista, Kalmytskii nauchnyi tsentr RAS. 456 p. (In Russ.)

Khabunova, E. E. (1998) Kalmytskaia svadebnaia obriadovaia poeziia [Kalmyk poetry of the wedding ritual]. Elista, Kalmytskoe knizhnoe izdatel'stvo. 224 p. (In Russ.)

Khabunova, E. E. (2005) Ochag. Obriady I obriadovyi fol'klor zhiznennogo tsikla kalmykov [The hearth: Rites and ritual folklore of the Kalmyk life cycle], ed. by A. V. Badmaev. Elista, AOr «NPP «Dzhangar». 206 p. (In Russ.)

Khabunova, E. E. (2006) Geroicheskii epos «Dzhangar»: poeticheskie konstanty bogatyrskogo zhiznennogo tsikla (sravnitel'noe izuchenie natsional'nykh versii) ["Jangar" as a heroic epic: the poetic constants of the heroic life cycle. A comparative study of national versions], ed. by G. Ts. Piurbeev. Rostov-na-Donu, Izdatel'stvo SKNTs VSh. 256 p. (In Russ.)

Shalkhakov, D. D. (1982) Sem'ia i brak u kalmykov (XIX - nachalo XX v.) Istoriko-etnograficheskoe issledovanie [Family and marriage among Kalmyks in the 19th and early 20th centuries: A historical and ethnographic study], ed. by S. I. Vainshtein. Elista, Kalmytskii nauchno-issledovatel'skii institute istorii, filologii I ekonomiki pri Sovete Ministrov Kalmytskoi ASSR. 86 p. (In Russ.)

Sharaeva, T. I. (2008) Ritual'naia «smert'» i «vozrozhdenie» nevesty v svadebnom obriade u kalmykov [A ritual of 'death' and 'rebirth' of the bride in the wedding rites of the Kalmyks]. In: Materialy Mezhdunarodnoi nauchnoi konferentsii «Oiraty i kalmyki v istorii Rossii, Mongolii i Kitaia» [Oirats and Kalmyks in the history of Russia, Mongolia and China]. Proceedings of the International conference (Elista, May 9-14, 2009): in 3 vols. / ed. by N. G. Ochirova. Elista, Kalmytskii institut gumanitarnykh issledovanii. Vol. 3. 165 p. Pp. 91-95. (In Russ.).

Sharaeva, T. I. (2009) «Smotriny zhenikha» v traditsionnoi kalmytskoi svad'be (po literaturnym dannym) ['Inspection of a prospective bridegroom' within the traditional Kalmyk wedding (a case study of literary sources)]. Izvestiia Rossiiskogo gosudarstvennogo pedagogicheskogo universiteta im. A. I. Gertsena, no. 117, pp. 89-94. (In Russ.)

Sharaeva, T. I. (2018a) «A «plokhuiu» sheiu my ostavim doma» (o simvolike sheinykh pozvonkov v svadebnoi obriadnosti kalmykov) ['And the 'bad' neck we shall leave back at home...': The symbolism of sheep neck bones within Kalmyk wedding rites revisited)]. Oriental Studies, no. 4, pp. 75-85. (In Russ.) DOI: 10.22162/2619-09902018-38-4-75-85

Sharaeva, T. I. (2018b) «Kogda govoriat o svad'be, to dazhe i issokhshii cherep katitsia» (k voprosu o znachenii baran'ei golovy v svadebnykh obriadakh). ["When they talk about wedding, even a wizened skull does roll": On the symbolism of a ram's head in the wedding ritual]. Mongolovedenie, no. 2 (13), pp. 20-34. (In Russ.) DOI: $10.22162 / 2500-1523-2018-13-22-37$

Sharaeva, T. I. (2010) Svadebnaia obriadnost' [Wedding rites]. In: Kalmyki [Kalmyks], ed. by E. P. Bakaeva, N. L. Zhukovskaia. Moscow, Nauka. 568 p. Pp. 249-270. (In Russ.)

Sharaeva, T. I. (2011) Obriady zhiznennogo tsikla kalmykov (XIX - nachalo XXI v.) [The ceremonies of the life cycle of the Kalmyks from the 19th to early 21st century]. Elista, ZAOr «NPP «Dzhangar». 223 p. (In Russ.)

Erdniev, U. E. (1970) Kalmyki (konets XIX - nachalo XX v.). Istoriko-etnograficheskie ocherki [Kalmyks in the end of the 19th and the beginning of the 20th centuries: Historical and ethnographic essays], ed. by G. G. Stratanovich. Elista, Kalmytskoe knizhnoe izdatel'stvo. 312 p. (In Russ.)

Erdniev, U. E. (1985) Kalmyki. Istoriko-etnograficheskie ocherki [Kalmyks: Historical and ethnographic essays]. 3nd ed. Elista, Kalmytskoe knizhnoe izdatel'stvo. 282 p. (In Russ.)

Erendzhenov, K. E. (1980) Tsetsn bulg [Rodnik mudrosti] [Spring of wisdom]. Elista, Kalmytskoe knizhnoe izdatel'stvo. 188 p. (In Kalm.)

Erendzhenov, K. E. (1985) Zolotoi rodnik: O kalmytskom narodnom tvorchestve, remeslakh i byte [The golden spring: On the Kalmyk folk art, crafts and life]. Elista, Kalmytskoe knizhnoe izdatel'stvo. 125 p. (In Russ.) 